\title{
IDOSAS COM ALGUM PROBLEMA DE SAÚDE E O RISCO DE QUEDAS
}

Janina Lied da Costa; UFSM; liedjanina@gmail.com

Sinara Porolnik; UFSM; porolnik@hotmail.com

Guilherme Tavares Arruda; UFSC; gui_tavares007@hotmail.com

Hedioneia M. F. Pivetta; UFSM; hedioneia@yahoo.com.br

\section{RESUM0}

Introdução: As quedas constituem uma alta proporção de morbimortalidade em idosos, além de trazer consequências negativas à qualidade de vida desses indivíduos. Diante do exposto, acredita-se ser fundamental conhecer o perfil das idosas para identificar possíveis vieses de risco às quedas. Objetivo: Verificar se idosas com algum problema de saúde têm risco de quedas. Métodos: Este trabalho é parte da Dissertação de mestrado vinculada ao projeto Guarda-chuva intitulado Funcionalidade, risco de quedas, nível de atividade física e controle postural em mulheres com e sem incontinência urinária, aprovado sob parecer CAAE: 63080416.0.0000.5346. Estudo transversal, composta por 41 idosas com média de $66,2 \pm 5,5$ anos de idade. Estas mulheres foram recrutadas nos grupos de atividades físicas do Núcleo Integrado de Estudos e Atenção à Pessoa Idosa. Os instrumentos utilizados foram a Ficha de avaliação elaborada pelos autores para delinear o perfil das idosas, o Questionário Internacional de Atividade Física (IPAQ) para qualificar o nível de atividade e o Teste Timed Up and Go (TUG) para avaliar o Risco de Quedas (RQ). Os dados foram analisados através da estatística descritiva com distribuição de frequências de valores absolutos e percentuais. Resultados: A maioria das idosas permanecia ativa $(97,6 \%)$, mesmo que $80,5 \%(n=33)$ delas apresentassem algum problema de saúde como hipertensão arterial sistêmica $(61,0 \%)$ e diabetes mellitus $(14,63 \%)$, e quanto ao risco de quedas, foi identificado baixo risco em $53,66 \%(\mathrm{n}=22)$. Conclusão: Nesta população, é possível dizer que idosas ativas podem reduzir o risco de sofrerem quedas, mesmo apresentando algum problema de saúde.

Palavras-chave: Acidentes por quedas; Assistência a idosos; Atividade motora; Dinâmica populacional; Envelhecimento; Prevenção de acidentes.

Agradecimentos: Ao financiamento da CAPES, a oportunidade dada pela UFSM, ao apoio e incentivo dos coautores e minha orientadora. 